
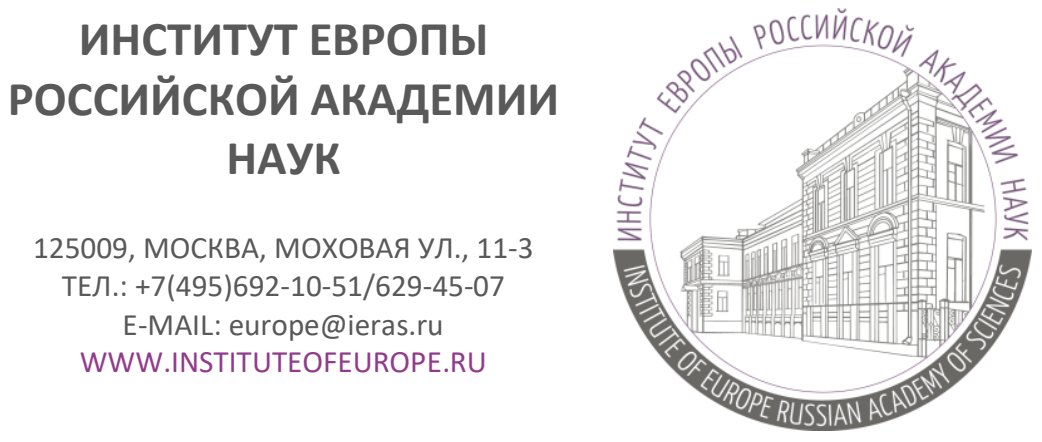

Аналитическая записка №12, 2020 (№195) ${ }^{1}$

\title{
Коронавирус: что может сделать и делает Европейский союз
}

\section{Людмила Олеговна Бабынина}

кандидат политических наук, ведущий научный сотрудник Отдела исследований европейской интеграции, руководитель Центра политической интеграции ИЕ РАН

\begin{abstract}
Аннотация. Тяжелая ситуация с распространением коронавируса в Европе закономерно привела к целому ряду ответных мер со стороны национальных правительств. Во многих государствах ЕС стали звучать обвинения в бездействии в адрес общеевропейских органов власти. Однако, они не имеют под собой достаточных оснований, поскольку функиии и возможности деятельности Евросоюза четко ограничены в основополагающем договоре ЕС. Автор анализирует, что именно и в каких областях может сделать и уже делает Евросоюз для борьбы с коронавирусом и его последствиями, где его действия наиболее эффективны, и к каким результатам привели односторонние меры государств-иленов.
\end{abstract}

Ключевые слова: Европейский союз, коронавирус, разделение компетенций, Европейская комиссия, государства-члены, общеевропейская солидарность.

\section{Компетенции Европейского союза и государств-членов}

Возможность осуществлять какие-либо действия и принимать законы в рамках европейского интеграционного проекта зависит от полномочий его участников. Договор о функционировании Европейского союза (ДФЕС) четко определяет сферы

\footnotetext{
${ }^{1}$ DOI: http://doi.org/10.15211/analytics 122020
} 
компетенций ЕС и государств-членов ${ }^{2}$, разделяя их на исключительную компетенцию Союза, когда решения принимают только на уровне ЕС, совместную компетенцию Евросоюза и государств-членов, когда существует разделение полномочий, и компетенцию национальных государств, где ЕС может выполнять только действия по поддержке и координации.

Здравоохранение (за исключением общих норм по охране труда) относится к компетенции государств-членов, в этой сфере нет обязательного к исполнению наднационального законодательства. В статье 168 ДФЕС прописано, что в обязанности государств-членов входит «управление службами здравоохранения и медицинское обслуживание», а Союз должен «уважать ответственность государств-членов за определение своей политики в области здравоохранения, в организации и предоставлении медицинских услуг и медицинского обслуживания». Со своей стороны ЕС может поддерживать усилия государств-членов в сфере здравоохранения, давать рекомендации, а также должен координировать их сотрудничество между собой. Институты ЕС могут принимать «стимулирующие меры, направленные на охрану и улучшение здоровья человека», в том числе, для борьбы с серьезными трансграничными угрозами для здоровья, их мониторингом и ранним предупреждением, но «исключая любую гармонизацию законов и нормативных актов государств-членов» ${ }^{3}$.

Таким образом, сфера здравоохранения находится полностью в зоне ответственности государств-членов ЕС, которые имеют полное право не прислушиваться к рекомендациям институтов Союза. Следует также учитывать, что национальные системы здравоохранения в странах ЕС сильно отличаются друг от друга как по качеству предоставляемых услуг, так и по организации самих систем, а Евросоюз не имеет полномочий для их гармонизации.

В то же время Европейский союз имеет значительные полномочия в сферах смешанной компетенции, в частности, в рамках реализации четырех свобод Единого внутреннего рынка (ЕВР) ЕС, в области экономической и бюджетной политики, в регулировании пересечения границ, и исключительные полномочия в рамках денежно-кредитной политики стран зоны евро, где решения принимает независимый Европейский центральный банк (ЕЦБ). Набор возможных действий Евросоюза в данных сферах весьма широк.

\section{Вспышка коронавируса и реакция государств-членов ЕС}

В ЕС вспышка коронавируса началась на севере Италии и достаточно быстро распространилась на другие страны. Помимо Италии, где сложилась катастрофическая ситуация, среди наиболее пострадавших оказались Испания, Франция и Германия, однако заболевшие новым вирусом есть во всех странах Европы. При этом не все

\footnotetext{
${ }^{2}$ Consolidated version of the Treaty on the functioning of the European Union. Arts. 2-6. Official Journal of the European Union C 326. 26.10.2012. Pp. 50-53.

${ }^{3}$ Ibid. Art.168. Pp. 122-124.
} 
системы здравоохранения оказались готовы к наплыву тяжелобольных пациентов. Лучше других с кризисной ситуацией справляется Германия. Страны Евросоюза начали предпринимать односторонние меры по предотвращению распространения вируса: в наиболее пострадавших регионах был объявлен карантин или режим самоизоляции, что привело к резкому снижению или полному прекращению экономической активности. Только две страны ЕС, Нидерланды и Швеция, до сих пор придерживаются иного подхода к борьбе с коронавирусом и не закрывают общественные места, рассчитывая на выработку коллективного иммунитета у населения.

Другим методом борьбы с распространением новой инфекции стало введение национальными правительствами проверок на границах и ограничение свободы передвижения людей и даже товаров. Первыми свои границы для граждан других стран EC закрыли Чехия, Польша и Эстония. Польша запретила даже транзит грузовых автомобилей через свою территорию. Постепенно большинство стран ЕС в одностороннем порядке ввело пограничный контроль и различные ограничения для свободного передвижения граждан ЕС. Помимо этого Германия, Франция и Чехия ввели ограничения на экспорт, в том числе в страны ЕС, защитного медицинского оборудования.

Согласно положениям Шенгенского кодекса о границах ${ }^{4}$, возобновление пограничного контроля внутри шенгенской зоны в случае экстренной опасности для государствчленов допустимо, а коронавирус может быть определен как «болезнь с эпидемическим потенциалом» и, согласно статье 29 Директивы о свободе передвижения ${ }^{5}$, может оправдывать ограничение свободы передвижения. Однако подобные действия должны быть соизмеримы как с самой угрозой, так и с последствиями их применения. Они не должны нарушать право ЕС и угрожать функционированию Единого внутреннего рынка ${ }^{6}$. Введенные ограничения привели к серьезным нарушениям в товарообороте внутри Евросоюза и Шенгенской зоны, огромным пробкам на границах и проблемам у рядовых граждан ЕС, находящихся за пределами своих государств. Оценивая параметры их применения, эксперты брюссельского Центра европейских политических исследований доказывают, что ограничительные меры чрезмерны и не соответствуют праву $\mathrm{EC}^{7}$.

На начальном этапе распространения коронавируса в Европе государства-члены ЕС принимали несогласованные односторонние решения и проявили мало солидарности как друг с другом, так и с пострадавшей сильнее других Италией.

\footnotetext{
${ }^{4}$ Regulation (EU) 2016/399 of the European Parliament and of the Council of 9 March 2016 on a Union Code on the rules governing the movement of persons across borders (Schengen Borders Code). Official Journal of the European Union L 77. 23.03.2016. Arts. 25-35.

${ }^{5}$ Directive 2004/38/EC of the European Parliament and of the Council of 29 April 2004 on the right of citizens of the Union and their family members to move and reside freely within the territory of the Member States amending Regulation (EEC) No 1612/68. Official Journal of the European Union L 158, 30.4.2004. Pp. 77-123.

${ }^{6}$ Carrera S. and Luk N.Ch. Love thy neighbour? Coronavirus politics and their impact on EU freedoms and rule of law in the Schengen Area. CEPS. No. 2020-04, April 2020. URL: https://www.ceps.eu/cepspublications/love-thy-neighbour/ (дата обращения: 05.04.2020)

${ }^{7}$ Ibid. P. 39-40.
} 


\section{Действия Европейского союза}

Еще в феврале руководящие органы ЕС были не слишком активны, тем более что вмешиваться в принимаемые государствами-членами действия в области здравоохранения у них нет полномочий. Но по мере разрастания пандемии и осознания масштаба экономических и гуманитарных последствий, Евросоюз, в первую очередь в лице Комиссии и ЕЦБ, стал принимать энергичные меры для их купирования и оказания помощи государствам-членам. Действия институтов ЕС привели к значительной корректировке политики государств-членов, и вместе они многое сделали для исправления сложившейся ситуации. В большинстве стран появилось понимание того, что кризис может быть разрешен только путем сочетания национальных мер и европейского сотрудничества ${ }^{8}$.

Действия институтов ЕС по борьбе с коронавирусом и его последствиями в настоящее время сосредоточены на трех сферах: усиление координации в области здравоохранения, разблокирование трансграничных перевозок и оказание экономической помощи государствам-членам. Для координации работы была создана Группа реагирования на коронавирус, в которую вошли пять членов Комиссии: Янез Ленарчич (управление кризисными ситуациями), Стелла Кириакидис (здравоохранение), Ильва Йоханссон (внутренние дела и юстиция), Адина Вэлян (транспорт) и Паоло Джентилони (экономика).

Для улучшения обеспечения индивидуальными средствами защиты и медицинским оборудованием был задействован Механизм гражданской защиты EC, в рамках которого Комиссия создала стратегический запас (rescEU) изделий медицинского назначения (дыхательные аппараты и защитные маски), которые теперь могут получить государства-члены ${ }^{9}$. На эти цели было первоначально выделено 50 млн евро. Европейская Комиссия также учредила консультативную группу по COVID-19, в которую вошли эпидемиологи и вирусологи из различных государств ЕС. Кроме того, Евросоюз запустил программу исследований по поиску вакцины, разработке методов диагностики и лечения от новой инфекции. Финансирование данной программы, составляющее 140 млн евро, идет из различных источников, в том числе из бюджета ЕС через программу «Горизонт 2020», государственных и частных средств ${ }^{10}$.

Возобновление контроля на границах стало неприятной неожиданностью для политического руководства $\mathrm{EC}^{11}$, но в середине марта Комиссия признала законность этого решения со стороны ряда государств-членов и призвала граждан ограничить

\footnotetext{
${ }^{8}$ Gostyńska-Jakubowska A, Scazzieri L. The EU can emerge stronger from the coronavirus crisis. CER. 1.04. 2020. URL: https://www.cer.eu/in-the-press/eu-can-emerge-stronger-coronavirus-crisis (дата обращения: 05.04.2020)

9 European Commission. COVID-19: Commission creates first ever rescEU stockpile. URL: https://ec.europa.eu/commission/presscorner/detail/en/ip_20_476 (дата обращения: 05.04.2020)

${ }^{10}$ Bulletin Quotidien Europe. № 12438, 04.03.2020

${ }^{11}$ Thym. D. Travel Bans in Europe: A Legal Appraisal (Part I). Blog of the Odysseus Academic Network. URL: http://eumigrationlawblog.eu/travel-bans-in-europe-a-legal-appraisal-part-i/ (дата обращения: 05.04.2020)
} 
«несущественные поездки» ${ }^{12}$. Тогда же Комиссия предложила ввести фактический запрет на въезд в Шенгенскую зону граждан третьих стран на 30 дней. Это предложение было одобрено на видеоконференции Европейского совета 17 марта ${ }^{13}$. В то же время ЕК призвала страны ЕС к координации методов пограничного контроля, обеспечению прозрачности внутренних границ, в первую очередь для поставок жизненно необходимых товаров ${ }^{14}$. Комиссия предложила создать специальные «зеленые полосы» для грузовиков на пропускных пунктах, чтобы те теряли как можно меньше времени при пересечении внутренних границ ЕС. Поскольку в своевременных поставках товаров заинтересованы все государства-члены, предложения ЕК были восприняты положительно, и ситуация на границах постепенно стала улучшаться.

Значительные усилия ЕС прилагает для компенсации социально-экономических потерь от коронавируса и вынужденной изоляции населения. Прежде всего, Комиссия признала, что пандемия квалифицируется как «необычное событие, неподконтрольное правительству» ${ }^{15}$, что позволило активировать законодательство, разрешающее применять исключительные меры в экономической сфере.

Во-первых, Комиссия смягчила правила оказания государственной помощи, позволив странам ЕС предлагать ликвидность нуждающимся предприятиям. Сделано это было на основании статьи 107 (2) ДФЕС ${ }^{16}$, которая разрешает компенсировать компаниям ущерб, вызванный исключительными случаями, каким было признано распространение короновируса. Первой программу государственной помощи на утверждение Комиссии представила Дания ${ }^{17}$.

Во-вторых, ЕС приостановил применение фискальных правил Пакта стабильности и роста $^{18}$, что позволило государствам-членам увеличить бюджетный дефицит для оказания непосредственной помощи пострадавшим компаниям и работникам, а также увеличить расходы на здравоохранение и закупку медицинского оборудования.

\footnotetext{
${ }^{12}$ Communication from the Commission. COVID-19: Temporary Restriction on Non-Essential Travel to the EU. $\operatorname{COM}(2020) \quad 115 \quad$ final. Brussels, 16.3.2020. URL: https://eur-lex.europa.eu/legalcontent/EN/TXT/?uri=COM:2020:115:FIN (дата обращения: 05.04.2020)

${ }^{13}$ European Council. Conclusions by the President of the European Council following the video conference with members of the European Council on COVID-19. URL: https://www.consilium.europa.eu/en/press/pressreleases/2020/03/17/conclusions-by-the-president-of-the-european-council-following-the-video-conference-

with-members-of-the-european-council-on-covid-19/ (дата обращения: 05.04.2020)

${ }^{14}$ European Commission. COVID-19. Guidelines for border management measures to protect health and ensure the availability of goods and essential services. URL: https://ec.europa.eu/homeaffairs/sites/homeaffairs/files/what-we-do/policies/european-agenda-migration/20200316_covid-19-guidelinesfor-border-management.pdf (дата обращения: 05.04.2020)

15 European Commission. COVID-19: Commission sets out European coordinated response. URL: https://ec.europa.eu/commission/presscorner/detail/en/ip_20_459 (дата обращения: 05.04.2020)

${ }^{16}$ Consolidated version of the Treaty on the functioning of the European Union. Arts. 107(2). Official Journal of the European Union C 326. 26.10.2012. P. 91.

${ }^{17}$ Bulletin Quotidien Europe. № 12445, 13.03.2020

${ }^{18}$ European Council. Conclusions by the President of the European Council following the video conference with members of the European Council on COVID-19. URL: https://www.consilium.europa.eu/en/press/pressreleases/2020/03/17/conclusions-by-the-president-of-the-european-council-following-the-video-conferencewith-members-of-the-european-council-on-covid-19/ (дата обращения: 05.04.2020)
} 
В-третьих, 18 марта ЕЦБ объявил ${ }^{19}$ о принятии Программы срочного выкупа активов в условиях пандемии (Pandemic Emergency Purchase Programme - PEPP) на сумму 750 млрд евро. Цель программы - выкуп облигаций и ценных бумаг государственного и частного сектора для смягчения экономического ущерба.

B-четвертых, Комиссия инициировала ряд шагов ${ }^{20}$ для помощи пострадавшим малым и средним предприятиям, а также самозанятым работникам в странах Евросоюза. В рамках бюджета ЕC будут использованы инструменты для поддержки этих предприятий ликвидностью, что дополнит меры, принимаемые на национальном уровне. В частности, 1 млрд евро будет направлен в Европейский инвестиционный фонд, чтобы стимулировать предоставление банками ликвидности малым и средним предприятиям. Комиссия хотела бы также предоставить кредитные каникулы заемщикам, пострадавшим от кризиса.

Другое предложение Комиссии связано с использованием средств структурных фондов ЕС для инвестирования в экономику пострадавших стран. Политика сплочения позволяет направить на эти цели 37 млрд евро. Страны ЕС смогут не возвращать неизрасходованные ранее средства структурных фондов (около 8 млрд евро) и использовать их в дополнение к 29 млрд евро, выделенных на этот год. Для поддержки уволенных работников и самозанятых лиц также можно задействовать средства Европейского фонда адаптации к глобализации, в 2020 г. они составят 179 млн евро. Кроме того, Комиссия предлагает расширить сферу деятельности Фонда солидарности ЕС для помощи наиболее пострадавших государствам-членам, что сделает доступными еще 800 млн евро в 2020 году.

Среди других мер Европейской комиссии стоит отметить запуск ускоренной совместной процедуры закупок медицинских товаров и продление сроков подачи заявок для итальянских фермеров на финансовую поддержку в рамках Общей сельскохозяйственной политики. Для особенно сильно пострадавшей отрасли авиационных перевозок временно отменено действие регламента ЕС 95/93, по которому авиакомпании должны использовать не $80 \%$ мест в аэропортах в течение определенного периода времени, чтобы удержать их в соответствующем периоде следующего года. В условиях почти полного прекращения авиасообщения выполнять данное требование авиакомпании не могли и несли огромные убытки. Опираясь на Руководящие принципы Комиссии ${ }^{21}$, Германия и Франция отменили запрет на экспорт медицинского оборудования в другие страны $\mathrm{EC}^{22}$. После этого в Италию были

\footnotetext{
${ }^{19}$ European Central Bank. ECB announces $€ 750$ billion Pandemic Emergency Purchase Programme (PEPP). URL: https://www.ecb.europa.eu/press/pr/date/2020/html/ecb.pr200318_1 3949d6f266.en.html (дата обращения: 05.04.2020)

20 European Commission. COVID-19: Commission sets out European coordinated response. URL: https://ec.europa.eu/commission/presscorner/detail/en/ip_20_459 (дата обращения: 05.04.2020)

${ }^{21}$ European Commission. COVID-19. Guidelines for border management measures to protect health and ensure the availability of goods and essential services. URL: https://ec.europa.eu/homeaffairs/sites/homeaffairs/files/what-we-do/policies/european-agenda-migration/20200316_covid-19-guidelinesfor-border-management.pdf (дата обращения: 05.04.2020)

${ }^{22}$ Bulletin Quotidien Europe. № 12447, 16.03.2020
} 
направлены миллионы масок и других защитных средств, а германские больницы начали принимать пациентов с коронавирусом из Франции и Италии.

Несмотря на активные действия институтов ЕС в марте, многие проблемы, связанные с преодолением последствий пандемии, остаются нерешенными. Наиболее пострадавшие страны, в первую очередь Италия и Испания, призвали создать на уровне ЕС механизм так называемых коронабондов, чтобы разделить долговое бремя между всеми государствами-членами. Однако, как и во время финансового кризиса 2008 г., против выступили Германия, Нидерланды, Австрия и Финляндия. Тогда Комиссия и ряд государств-членов выступили с инициативой создания общеевропейской программы страхования от безработицы SURE, с бюджетом до 100 млрд евро, поскольку рост безработицы будет высок во всех странах ЕC, особенно в наиболее пострадавших. Программу должен одобрить Совет ЕС. Если государства-члены согласятся на реализацию такого проекта, он может стать хорошим вкладом в укрепление общеевропейской солидарности.

\section{Выводы}

Ситуация с противодействием коронавирусу и его последствиям в ЕС в очередной раз подтвердила существующее противоречие: с одной стороны, для более эффективного ответа на общие для Евросоюза вызовы ему необходимо иметь больше полномочий, с другой, государства-члены не готовы их передавать, особенно в политически чувствительных сферах.

В рамках своих полномочий Евросоюз старается отвечать на кризис, вызванный пандемией. Очевидно, что реакция ЕС на распространение коронавируса была запоздалой, но меры, принимаемые институтами Евросоюза для смягчения последствий пандемии, можно оценить как вполне эффективные. Из трех основных направлений деятельности ЕС - здравоохранение, мобильность и экономика - именно в последней приняты наиболее действенные меры, что во многом обусловлено объемом имеющихся здесь у Союза полномочий и инструментов, а также объективной заинтересованностью государств-членов в получении финансовой и иной помощи.

Нарушение функционирования Единого внутреннего рынка ЕС (ограничение свободы передвижения лиц и товаров) стало серьезным вызовом для объединения. Односторонние действия государств-членов, направленные на закрытие внутренних границ, запрет экспорта медицинского оборудования и транзита автотранспорта не просто привели к экономическим потерям, но и вошли в противоречие с правовой системой ЕС. Вероятно, и в будущем Союзу придется бороться с попытками подорвать верховенство закона.

Коронакризис нанес огромный ущерб внутренней солидарности ЕC, ее сохранение стало отдельной важной проблемой. Парадоксально, но одной из главных задач Евросоюза стала борьба с эгоизмом его членов. В итоге, институты ЕС и государствачлены сделали многое для исправления допущенных ошибок. Однако урон, в том числе и в глазах общественного мнения, остается большим. 
Для преодоления социально-экономических последствий пандемии необходимо сочетать усилия национальных и наднациональных органов. Отсутствие тесного и скоординированного сотрудничества в рамках объединения и односторонние меры на национальном уровне только усугубляют кризис и не могут стать решением проблем. Преодоление политических последствий и дальнейшее развитие интеграционного проекта будет зависеть от того, насколько объективно будут представлены результаты общеевропейского взаимодействия гражданам ЕС.

Действия ЕС по борьбе с социально-экономическими последствиями пандемии позволили государствам-членам направить реальные денежные средства непосредственно пострадавшим предприятиям и работникам. Возможно, такой опыт был бы интересен и для России, где на фоне пандемии также ожидается высокий рост безработицы.

\begin{abstract}
The spread of coronavirus in Europe has naturally led to responses from national governments. Many EU countries accused the European Union of inaction. But the functions and capabilities of the European Union are clearly limited in the Founding Treaty. The author analyzes what exactly and in what areas the EU is able and already doing to combat the coronavirus and its consequences, where its actions are the most effective and what consequences have resulted from unilateral actions of member-states.
\end{abstract}

Keywords: European Union, Coronavirus, division of competences, European Commission, member states, pan-European solidarity.

Дата выпуска: 6 апреля 2020 года.

Материал доступен для скачивания по адресу: www.instituteofeurope.ru/publications/analytics 